\title{
PALISADED AND ENCAPSULATED NEUROMA (PEN) - CASE REPORT
}

\author{
S. Shtilionova ${ }^{1}$, P. Drumeva ${ }^{1}$, M. Balabanoval ${ }^{2}$, I. Krasnaliev ${ }^{3}$ \\ 1) Department of dermatology and venereology, Medical University - Varna \\ 2) Department of dermatology and venereology, Medical University - Sofia \\ 3) Department of pathology, Medical University - Varna
}

\section{SUMMURY}

Palisaded and encapsulated neuroma (PEN) is uncommon firstly desribed by Reed in 1972 .

It presents by solitary elasic tends, asymptomatic papules, 2-6 $\mathrm{mm}$ large.

Palisaded and encapsulated neuroma (PEN) is a benign tumor and does not give recidives. (PEN)

Key words: Palisaded and encapsulated neuroma

\section{CASE REPORT}

Palisaded and encapsulated neuroma is rare cutaneous disorder. Wich is predominantly localized on the face and is commonly misdiagnosed as basal cell carcinoma, naevos or schwanoma

56 years old male with a non painful lesion on the basis of the nose that in 3 months enlarged its diameter. No other serious systemic diseases are announced.

From the dermatological status:

A solitary round lesion, slightly above the surrounding skin, tight, localized laterally at the basis of the nose, with diameter $0,5 \mathrm{~cm}$. The covering skin is intact.

From the biopsy:

- macroscopic signs:rhomboic piece of skin with around formation under the epidermis $0,5 / 0,5 \mathrm{~cm}$. Totaly taken with the biopsy

- microscopic signs: well defined, intradermal round, nodular lesion,



partially capsulated, as the capsule is almost not seen in the epidermal aspect,

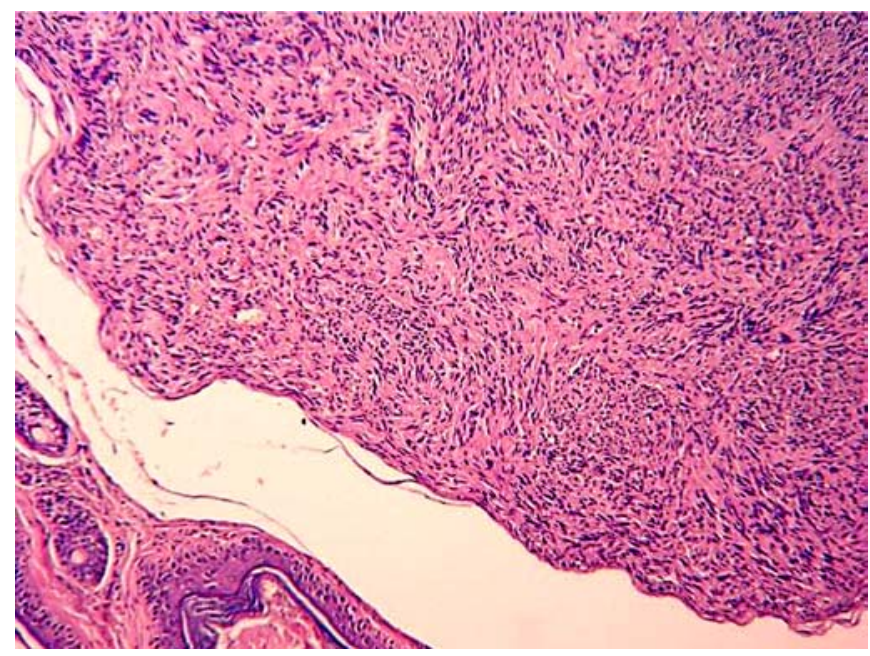

and well seen in the basal parts. 


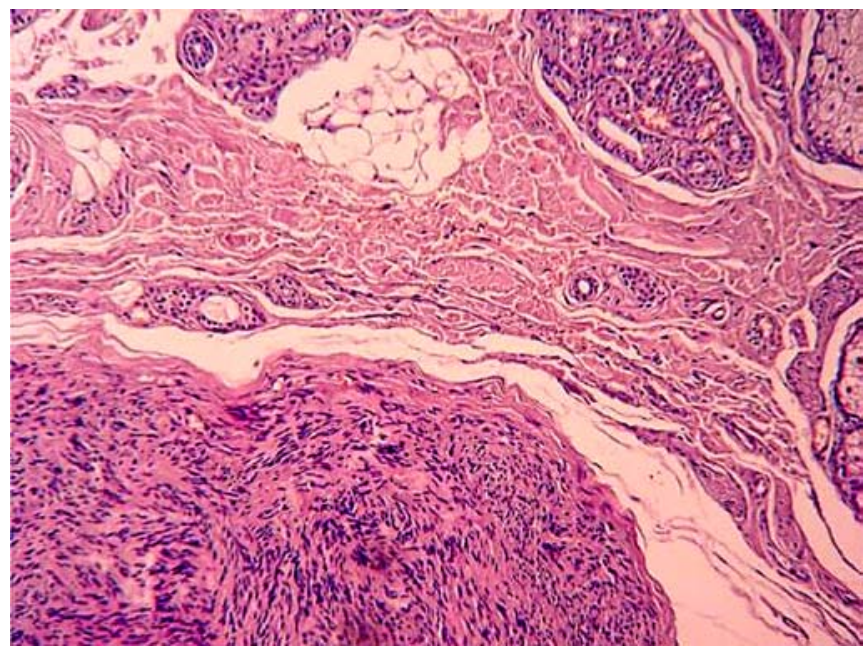

The lesion consists of crossing in different areas fascicles, forming drawnout cells, with slightly ondulated nuclei. The chromatine is normally dispersed, the cytoplasm is eosinophylic. Some of the drawnout nuclei are with a tendency to paliseded order, but without forming werocai corpuscles. There is a lack of mytotic activity, signs of cellular atypism, inflammatory and degenerative changes.

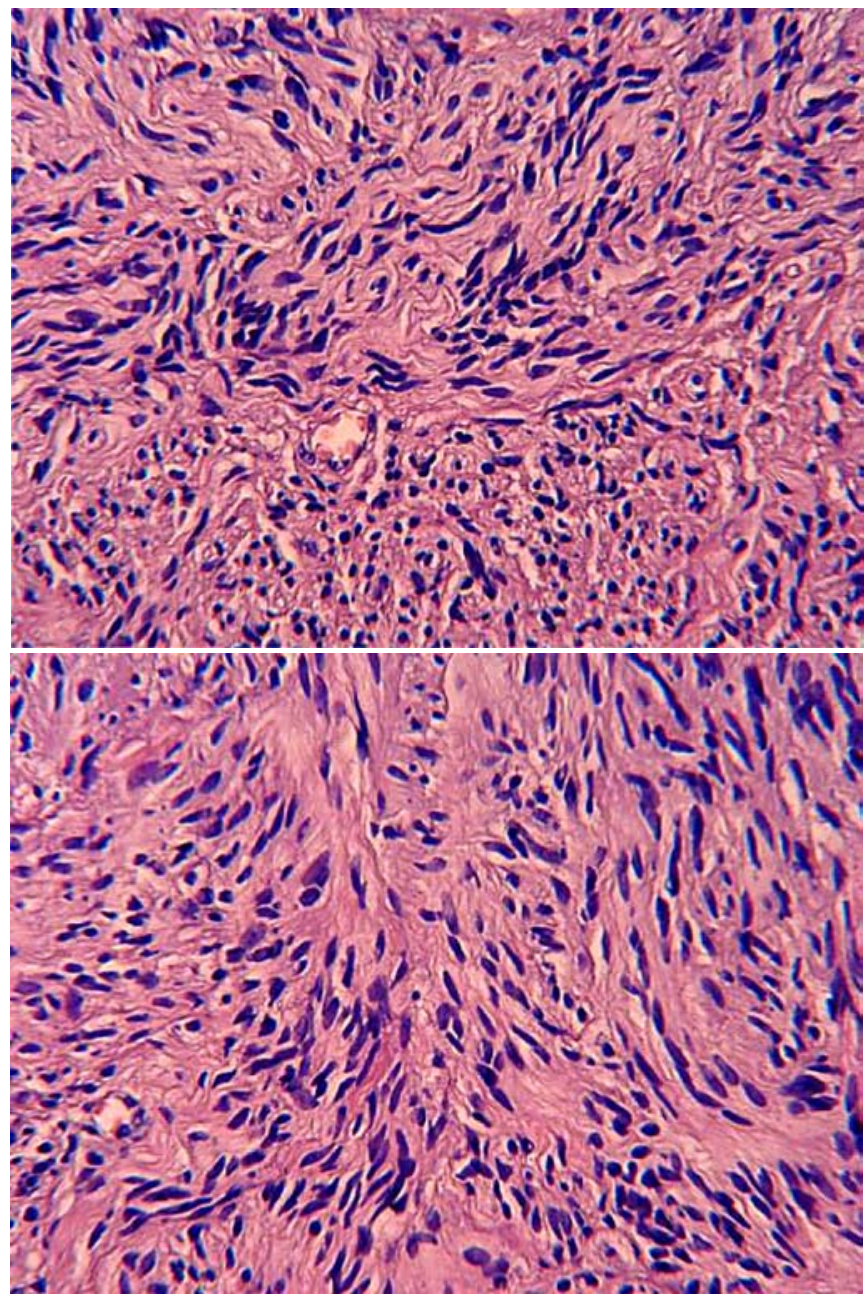

Immuno-hysto-chemical study shows a difuse expression of S-100 protein.

\section{DISCUSSION}

This uncommon tumor is firstly described by Reed, Fine and Meltzer in Archives of Dermatology in 1972 (7). It presents as a solitary mass on the face of middle-aged patients. It has a fine capsule or is at least well-separated from the adjacent dermis. Fascicles of neurons interwine together.There is palisading or orderly arrangement of the nuclei in some areas of the tumor. The bundles when cut in cross-section do not show the cytoplasmic clarity seen in leiomyoma $(1,2,3)$.

In about $90 \%$ of the cases the lesions are located on the face, but rarely they can be seen on the shoulders, hands, nazal mucosis and glans penis $(4,5,6)$.

Clinical signs include solitary, elastic tends, asymptomatic papules, $2-6 \mathrm{~mm}$ large. No teleangiectasia are seen, but only ulcerations after a trauma. Most often these tumors are diagnostified as basocellular carcinomas, dermal naevi, epidermal cysts, fibromas, small adnexial carcinomas.

PEN is a benign tumor and does not give recidives.

\section{CONCLUSION}

1. The presents of a tumor-like formation in the face area requires diagnostic confirmation targeting: basocellular carcinomas, dermal naevi, epidermal cysts, fibromas, small adnexial carcinomas.

2. The diagnostic conclusion should be combined with total cure excision of tumor tissue.

3. Immuno-hysto-chemical study with S-100 protein radically excluses melanocytic proliferation and should be combined in research methods. 


\section{REFERENCES:}

1. Barnhill Raymond L., Crowson A. Neil, Textbook of Dermatopathology, Edition: 2, illustrated, revised, McGrawHill Professional, 2004, 893-915

2. Dubovy S, Clark B. Palisaded encapsulated neuroma (solitary circumscribed neuroma of skin) of the eyelid: report of two cases and review of the literature. Br J Ophthalmol. 2001 Aug; 85(8): 949-5

3. Golod O, Soriano T, Craft N.
Palisaded encapsulated neuroma-A classic presentation of a commonly misdiagnosed neural tumor. J Drugs Dermatol. 2005 JanFeb; 4(1): 92-4.

4. Magnusson B. Palisaded encapsulated neuroma (solitary circumscribed fibroma) of the oral mucosa. Oral Surg Oral Med Oral pathol Oral Radio Endod. 1996 Sep; 82(3):302-4.

5. Mayorga M, Acebo E, Val-Bernal J.

Palisaded encapsulated neuroma of the nasal fossa. Otolaryngol Head Neck Surg. 1998 Jul;119(1);141-3.

6. Navarro M, Vilata J, Requena C, Aliaga A. Palisaded encapsulated neuroma (solitary circumscribed neuroma) of the glans penis. Br J Dermatol. 2000 May; 142(5):1061-2.

7. Reed R, Fine R, Meltzer H. Palisaded encapsulated neuromas of the skin. Arch Dermatol 1972 Dec; 106(6):865-70.

Address for correspondence:

Dr. Siana Shtilionova, Department of dermatology and venereology, Medical University - Varna 55, Marin Drinov str., 9000 Varna, Bulgaria E-mail: shtilionova@abv.bg 